\title{
A emergência da noção de comportamento simbólico em neuropsicopatologia
}

\author{
Danilo Saretta Verissimo \\ Universidade Estadual Paulista de Assis
}

\begin{abstract}
Resumo
Neste artigo, apresentamos a noção de comportamento simbólico conforme estudos em neuropsicopatologia das primeiras décadas do século passado realizados, particularmente, no seio de investigações sobre as afasias. Tomamos como eixo condutor a presença da noção em questão na primeira obra de Merleau-Ponty, "A estrutura do comportamento". Com base nas pesquisas de Gelb e Goldstein, o filósofo apropria-se da semântica do símbolo e caracteriza a corporalidade humana a partir da sua capacidade de ultrapassar o caráter imediato das situações vividas. Mostramos, ainda, que a circunscrição do comportamento simbólico esteve condicionada a mudanças teórico-metodológicas que tornaram possível a passagem de concepções localizacionistas a atitudes globalistas diante dos eventos patológicos de origem cerebral.
\end{abstract}

Palavras-chave: função simbólica; atitude categorial; afasia; Merleau-Ponty.

\begin{abstract}
The emergence of the notion of symbolic behavior in neuropsychopathology. In this article, we present the notion of symbolic behavior in accordance with neuropsychopathology research from the first decades of the past century, carried out particularly in the context of aphasia research. The guiding axis was the presence of this notion in the first work by Merleau-Ponty, "The structure of behavior". Based on research by Gelb and Goldstein, the philosopher takes ownership of the semantics of the symbolic and characterizes human corporality based on its capacity to move beyond the immediate nature of the experienced situations. We also show that the circumscription of symbolic behavior was conditioned by theoretical-methodological changes that permitted the passage from localizationist conceptions to globalist attitudes in view of pathological events of cerebral origin.
\end{abstract}

Keywords: symbolic function; categorial attitude; aphasia; Merleau-Ponty.

$\mathrm{N}$ este artigo, temos por objetivo apresentar a noção de comportamento simbólico tal como elaborada em meio aos estudos em neuropsicopatologia das primeiras décadas do século passado, particularmente no seio dos estudos sobre as afasias. Tomamos como eixo condutor a presença da noção em questão na primeira obra de Maurice Merleau-Ponty, "A estrutura do comportamento". Neste livro, com base nas pesquisas de Gelb e Goldstein, o filósofo apropria-se da semântica do símbolo e caracteriza a corporalidade humana a partir da sua capacidade de ultrapassar o caráter imediato das situações vividas. Vale frisar que, conforme nossa referência a Merleau-Ponty deixa presumir, os estudos sobre a consciência simbólica no campo da neuropsicopatologia do início do século XX tiveram grande influência sobre a filosofia ${ }^{2}$, a antropologia e a psicologia (Karsenti, 1997), o que torna ainda maior sua relevância em termos epistemológicos e históricos.

Questões teórico-metodológicas em neuropsicopatologia
Os estudos clássicos em psicopatologia possuem um caráter localizacionista que espelha o espírito atomista que reinava na fisiologia e na psicologia até o início do século XX. A uma lesão cerebral circunscrita eram correlacionados déficits funcionais também circunscritos, seja na linguagem, no reconhecimento visual, na coordenação motora e demais funções. Para MerleauPonty (1942/1967), o desenvolvimento das pesquisas em neuropsicopatologia expõe, então, o quanto os estudos pioneiros subestimavam algumas dificuldades essenciais. Primeiramente, a de se localizar corretamente uma lesão cerebral, que pode se estender bem além dos limites nos quais ela é claramente observável. Em segundo lugar, o problema de se localizar uma determinada função orgânica no tecido cerebral, dado que funções diferentes podem ser prejudicadas por lesões localizadas aparentemente em áreas cerebrais idênticas, e uma mesma função pode ser alterada por lesões localizadas, notavelmente, em áreas distintas do tecido nervoso central. A terceira dificuldade referese à definição adequada da patologia estudada e da função normal à qual ela corresponde. 
A superação dos limites dessas pesquisas pioneiras não se deve, fundamentalmente, a avanços técnicos em termos de procedimentos cirúrgicos e laboratoriais, mas, sim, a reflexões metodológicas no que tange à teoria do conhecimento biológico (Merleau-Ponty, 1942/1967). Em patologia geral, a formulação de quadros nosológicos, que visam explicar os diversos sintomas observáveis a partir de um distúrbio fundamental, mostra-se funcional. Nesse campo, estão em jogo certos processos físicoquímicos que deixam de responder a determinados estímulos, mesmo em circunstâncias as mais variadas. Dessa maneira os sintomas de uma determinada doença podem ser identificados de modo quase inequívoco. O patologista opera uma análise que se atém a fragmentos "reais" do comportamento patológico, posto que se enumeram as reações conservadas e as reações abolidas no organismo doente (Merleau-Ponty, 1942/1967). Esse tipo de análise permite a construção de um "encadeamento real de efeitos e de causas observáveis” (Merleau-Ponty, 1942/1967, p. 67) que conduz nosso olhar através das manifestações superficiais até a perturbação essencial, que, normalmente, possui um locus preciso no corpo. O estudo das patologias mentais não poderia se desenvolver, porém, sem que novos fundamentos metodológicos viessem substituir a posição clássica dos problemas e métodos de que se dispunha. Com efeito, o "método de análise real e de explicação causal” (Merleau-Ponty, 1942/1967, p. 67) mostra-se infrutífero no contexto das disfunções mentais. É o que revela a história dos estudos sobre a afasia, sobre a apraxia e sobre a agnosia. Os estudos iniciais dessas patologias explicavam-nas pela extinção de conteúdos do comportamento, ou, para falar a linguagem da psicologia empirista, pela perda de conteúdos específicos de consciência, todos sustentados por associações adquiridas.

Com base em Merleau-Ponty (1942/1967), vemos que, no tocante à teoria do reflexo, os dados experimentais repetidamente contradiziam a ideia da solidariedade entre receptores especializados, centros corticais especializados e efetores também especializados. Vemos, ainda, que a teoria clássica não abandonava suas diretrizes ao interpretá-los. Ao invés disso, eram elaboradas hipóteses auxiliares que, se bem analisadas, não passavam de construções teóricas cujo objetivo era assegurar ao menos um mínimo acordo entre a doutrina e os dados examinados, e, em última instância, salvaguardar a noção tradicional de reflexo. A riqueza dos fatos era encoberta por uma impregnação teórica que se mostrava mais poderosa. Estamos face aqui a um fenômeno de ordem epistemológica bem semelhante ao que ocorrera durante um primeiro período dos estudos sobre a afasia. Um espírito anatômico de caráter atomista dominava tanto a interpretação dos sintomas afásicos quanto a elaboração teórica dos fenômenos anátomo-fisiológicos que pudessem ser designados como a origem do comportamento patológico (Merleau-Ponty, 1942/1967). Assim, fatos que clamavam pela hipótese de um funcionamento global eram interpretados sem que as noções atomistas fossem abandonadas. Aos poucos, sob a pressão das contradições entre os dados clínicos e as formulações teóricas que buscavam explicá-los, a concepção clássica das localizações cedeu espaço a uma atitude globalista diante do evento patológico de origem cerebral. Afinal, como observa Merleau-Ponty (1942/1967, p. 68), as “lesões do córtex raramente provocam perturbações eletivas que implicam isoladamente certos fragmentos do comportamento normal".

A abertura a essa concepção globalista apresentada por Merleau-Ponty (1942/1967) dependia de um novo gênero de análise, de caráter sintético, que desse conta dos aspectos concretos da descrição da pesquisa empírica, que visasse a compreensão da "fisionomia de um conjunto e sua lei imanente" (Merleau-Ponty, 1942/1967, p. 70) e não de uma análise que, desde o processo descritivo de um fenômeno qualquer, se mostrasse como o exercício de uma tomada de partido teórico, o que faz do próprio momento descritivo um exercício de teorização vindo a empobrecer justamente o contato do pesquisador com o fenômeno observado. Nesta nova perspectiva, que muitos autores (Binswanger, 1971; Minkowski, 1933/1995; Straus, 1966) identificam como uma espécie de fenomenologia aplicada, ou antropologia fenomenológica, a patologia pode deixar de ser um conteúdo do comportamento, algo que se observa, no sentido de vir a ser identificada a uma nova "estrutura de comportamento", uma alteração qualitativa que demanda um esforço de compreensão. A perturbação essencial e os sintomas deixam, então, de figurar numa relação de causa e efeito para expressarem, antes, uma "relação lógica de princípio a consequência ou de significado a signo" (MerleauPonty, 1942/1967, p.70), como veremos em Hughlings Jackson, e, sobretudo, nos estudos de Gelb e Goldstein.

\section{Notas sobre a história das afasias}

Forest (2005) argumenta que a definição da afasia não se refere apenas à história da medicina das perturbações da linguagem, mas, sobretudo, à história do conhecimento fisiológico do cérebro. Nesse sentido, e grosso modo, nossas notas contemplam três paradigmas concernentes ao funcionamento nervoso que marcaram a história das afasias: as concepções de cunho localizacionista, as concepções de cunho associacionista, e, por fim, as concepções de cunho globalista.

Franz Joseph Gall (1758-1828) é um pioneiro nas pesquisas que nos interessam aqui. Seus trabalhos, de caráter materialista, centravam-se na localização cerebral dos fenômenos psíquicos e no anseio de elaborar um mapa minucioso do cérebro (Goldstein, 1983; Kristensen, Almeida, \& Gomes, 2001). Forest (2005) mostra que a organologia de Gall foi elaborada sob o plano de fundo da questão das ciências do homem e das relações entre o físico e o moral tais como concebidas na perspectiva de Cabanis $(1956)^{3}$. Sob a égide das ciências do homem encontravam-se a fisiologia, a análise das ideias e a moral, mas as duas últimas eram subordinadas à primeira em uma antropologia que, em última instância, era uma antropologia física (Forest, 2005). Neste contexto, as teses de Gall giram em torno da especialização funcional das áreas do córtex cerebral humano. Para ele, os hemisférios cerebrais seriam constituídos por diversos órgãos independentes (Lecours \& Lhermitte, 1979). Ao lado de uma revolução anátomo-fisiológica, Gall desenvolve um discurso psicológico voltado para a psicologia das faculdades. Procedendo desse modo, ao invés de atrelar as especializações funcionais corticais a faculdades horizontais, tais como imaginação e memória, Gall constrói faculdades verticais, tais como talento musical, memória de palavras e talento para línguas. Suas 
pesquisas orientaram as investigações de Paul Broca sobre o substrato biológico da expressão verbal.

É aqui que se inicia, mais especificamente, a preocupação com a linguagem. Entre 1861 e 1865, Pierre Paul Broca (18241880) somou observações clínicas e anátomo-clínicas que lhe possibilitaram associar a integridade do lobo frontal cerebral esquerdo e a integridade da expressão verbal (Forest, 2005). Broca diagnosticara, em seus pacientes, lesados naquela região cerebral, perda da fala sem paralisia dos órgãos articuladores e sem comprometimento da inteligência, patologia que o pesquisador denominou afemia. Os pacientes eram incapazes de articular a fala por meio dos aparelhos motores normalmente envolvidos no fenômeno, isso apesar da integridade desses aparelhos. O mecanismo explicativo da patologia elaborado por Broca envolve uma memória verbal, isolada de outras atividades psíquicas e dependente de uma localização cerebral precisa (Goldstein, 1971a). De acordo com as teses associacionistas vigentes na época, Broca admitiu a existência de imagens verbais motoras, compostas por lembranças-imagens de palavras, de sons e de letras, e que seriam depositadas no centro motor da linguagem, ou seja, na área cerebral identificada por ele. A lesão dessa área levaria à supressão dessas imagens verbais motoras, impossibilitando, por conseguinte, o acionamento dos dispositivos motores da linguagem. Além do caráter inventivo dessa concepção de imagens-memória, Goldstein (1971a, p. 296) põe em relevo a concepção compartimentada dos mecanismos apresentados: "Para Broca, a memória verbal motora era uma memória especial 'dos movimentos necessários à articulação das palavras'; ela não possuía relação 'nem com as outras memórias, nem com o resto da inteligência"”.

A partir do isolamento de centros cerebrais ligados à linguagem, surgiu a preocupação com a associação entre eles. Henry Bastian (1837-1915), Ludwig Lichteim (1845-1928) e Jean Martin Charcot (1825-1893) figuram entre os principais pesquisadores de cunho associacionista (Kristensen et al., 2001). Por outro lado, é sobre a participação de Carl Wernicke (18481905) que focalizaremos nossa atenção. Wernicke estabeleceu uma relação causal entre lesões no giro temporal esquerdo e o que ele denominou afasia sensorial, a saber, perturbação na compreensão da linguagem devida à perda da memória das imagens auditivas das palavras (Lecours \& Lhermitte, 1979). Os afásicos sensoriais, ao contrário dos afásicos motores, falam muito, mas apresentam inadequações linguísticas e não compreendem bem a fala de outrem. Para Wernicke, a compreensão da fala era tão significativa quanto a sua produção, e a sua abolição tão significativa quanto o poder expressivo isolado por Broca. E, se na recepção das palavras temos um componente da linguagem, este componente possui, necessariamente, uma localização cerebral, considerava o pesquisador.

Wernicke já era herdeiro de um novo gênero de pesquisas, como as de Théodore Meynert (1833-1892), sobre os feixes de fibras nervosas associativas dos hemisférios cerebrais (Lecours \& Lhermitte, 1979). Assim, com base em observações clínicas e anátomo-clínicas, Wernicke pôde delimitar outro tipo de afasia relacionado a lesões de fibras que associam as áreas delimitadas por Broca e por ele mesmo: a parafasia, desordem da linguagem na qual vemos o paciente realizar inúmeros equívocos na construção das palavras. Assim, a integridade da linguagem não é mais atribuída a uma única área cerebral, mas a uma rede da linguagem que envolveria o lobo frontal cerebral esquerdo e o giro temporal esquerdo, além das fibras associativas que ligariam essas duas regiões cerebrais. A lesão de uma dentre essas partes acarretaria perturbações distintas da linguagem (Forest, 2005).

Até este ponto, os pesquisadores mais importantes no campo da afasia eram influenciados pela psicologia sensualista dos elementos, o que limitava o desenvolvimento teórico de questões relativas ao pensamento e à linguagem, malgrado a riqueza das observações realizadas. A função linguística era considerada como composição de imagens sensíveis advindas da associação de percepções ópticas, acústicas e cinestésicas. Além disso, essa concepção psicológica tinha um paralelo na fisiologia. Cada domínio de impressões sensíveis deveria contar com uma ancoragem bem delimitada no cérebro (Cassirer, 1972). Neste contexto, diversas dificuldades permaneciam intocadas. Como falar, por exemplo, de imagens visuais que não se referem aos símbolos literais mencionados por Husserl (1921/1963), às coisas concretas, mas a significações formais complementares, como as transmitidas pelas palavras "talvez" e "qualquer"? Como explicar a compreensão, por parte dos pacientes, de homônimos das palavras que lhes faltam? E como pensar o fato de que podemos escutar uma mesma palavra reproduzida por inúmeros locutores, que, no mais das vezes, produzem fenômenos sonoros apenas similares? Teríamos uma imagem verbal para cada uma

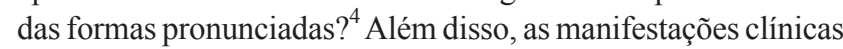
da afasia motora, ou afasia de Broca, põem os pesquisadores na presença caótica de atividades lacunares e de outras ainda possíveis para o paciente. Goldstein (1971a) comenta:

\begin{abstract}
Certamente, não é o acaso que decide o que o doente pode ou não dizer; podemos discernir uma escolha singular; além disso, ficamos espantados ao ver que o doente não realiza sempre todos os atos de linguagem que lhe seriam ainda possíveis, enquanto que, de outro lado, ele surpreende o observador ao executar atos dos quais ele acabava de se mostrar incapaz. Ao considerar as coisas de fora, tem-se a impressão de uma grande inconstância, que se atribui, frequentemente de modo equívoco, a efeitos de perturbações gerais, fadiga, etc. (p. 295)
\end{abstract}

Conforme comentário de Merleau-Ponty (1942/1967), seguindo-se os preceitos da patologia geral e a fidelidade aos princípios atomistas e associacionistas da época, médicos e pesquisadores recortavam, na observação do comportamento dos pacientes afásicos, os sintomas explicáveis a partir de uma suposta perturbação no armazenamento e na ativação das imagens verbais. Os sintomas excedentes eram atribuídos às lesões suplementares ou diminuídos em sua importância, sendo considerados secundários em relação às perturbações primárias. É assim que Wernicke podia afirmar que os sintomas parafásicos de seus pacientes, aos quais se atribuía o diagnóstico de afasia sensorial, eram causados pela "falta de correção inconsciente habitual devida à imagem sonora" (Wernicke, 1874, citado por Forest, 2005, p. 159).

Hughlings Jackson (1835-1911) figura nessa história das afasias como um divisor de águas. Isso porque, malgrado o fato do neurologista ser contemporâneo dos primeiros 
associacionistas, as noções de centros cerebrais circunscritos e de conexões nervosas possuem um papel meramente secundário em suas concepções sobre o sistema nervoso humano, a linguagem e a afasia. Para Jackson, a linguagem depende da integridade do cérebro, mas não deve ser considerada como uma atividade confinada a territórios particulares (Lecours \& Lhermitte, 1979). Os estados patológicos em neurologia, diz Jackson, revelam estados precedentes de organização nervosa. O autor afirma:

A doença mostra que a atividade mental superior ascende a partir de nossos estados mais organizados...que a vontade, a memória, etc, "vêm de baixo" e não se situam de maneira autocrática "acima", a governar o espírito; simplesmente, eles são, até o presente, o mais elevado, ou o último estado do nosso eu inteiro (Jackson, 1879, citado por Forest, 2005, p. 91).

A emancipação dos automatismos é a revelação das origens do ato voluntário a partir do recalque do ato mais primitivo em termos fisiológicos. Assim, a ideia de localização nervosa a qual se liga Jackson é a de localização fisiológica, em que o sistema cérebro-espinhal apresenta diferenças no tocante ao tipo de movimento elaborado, o movimento automático ou o movimento voluntário. Nesse mesmo sentido caminha sua lei de dissolução, que afirma a prioridade dos sistemas mais evoluídos, ou seja, os ligados aos processos de caráter voluntário, no percurso da desintegração do funcionamento nervoso no caso de lesão cerebral. A utilização mais complexa desse funcionamento é a primeira a ser atingida. Desse modo, se a privação ao exercício da função perdida constitui o que Jackson chama de sintomas negativos da doença, o exercício funcional que resta ao doente, ou seja, os sintomas positivos, não são causados pela doença, diz ele, e, sim, constituem o resultado da atividade que subsiste no sujeito portador de lesão cerebral.

Esta inversão que faz da doença pura privação e realça as atividades subsistentes é um aspecto revolucionário da compreensão patológica em Jackson. Ela revela a influência do evolucionismo de Spencer na obra do neurologista (Forest, 2005). Em Spencer, o desenvolvimento cerebral ao longo da ontogênese representa a evolução biológica do homogêneo ao complexo. Trata-se de um órgão de maturidade tardia cujo desenvolvimento subordina organizações completas, como as ações reflexas, a organizações menos determinadas e mais complexas. Além disso, Spencer dá particular importância aos "equilíbrios móveis", ou seja, mais frágeis, que caracterizam as diferenças funcionais entre os indivíduos de uma mesma espécie. Estes equilíbrios mais elevados devem, sempre, ser mais ou menos afetados pelas forças acidentais que cercam estes indivíduos. Jackson transpõe este princípio aplicado às espécies biológicas aos estados do sistema cérebro-espinhal. Em caso de lesão cerebral, os estados orgânicos "mais aptos", mais estáveis, contudo de nível inferior, possuem maiores possibilidades de permanecer atuantes. Forest (2005, p. 96) comenta: "Spencer é, portanto, a chave das distinções jacksonianas entre causar e permitir, entre 'condição negativa' e 'condição positiva' do paciente". É assim que, no que tange à linguagem, os signos negativos das lesões cerebrais correspondem à carência funcional associada à desorganização dos processos mais evoluídos e voluntários, enquanto os signos positivos correspondem ao funcionamento isolado das partes não lesadas, à sobrevivência de níveis inferiores de organização do organismo que garantem a expressão de processos mais primitivos e automáticos.

É a Jackson que se atribui a observação de que certas palavras podiam ser utilizadas pelos pacientes em determinados contextos, mas não em outros (Cassirer, 1972). Segundo Goldstein (1971a), aos processos linguísticos mais evoluídos, Jackson associou, então, a linguagem intelectual, representativa e voluntária, utilizada para responder a questões, para designar objetos, etc. Por outro lado, aos processos linguísticos mais primitivos, o autor associou a linguagem afetiva, emocional, ou involuntária, de caráter passivo em relação às intenções conscientes do indivíduo.

A partir de Jackson, foi possível uma expansão na consideração dos distúrbios observados nos pacientes afásicos. $\mathrm{O}$ estado patológico, antes circunscrito à linguagem, podia se estender ao campo mais geral do pensamento e da motricidade. Pierre Marie (1853-1940), além de combater a teoria das imagens verbais, exigia que os sintomas afásicos fossem interpretados em termos de modificação geral da inteligência (Goldstein, 1971a). Já Henry Head (1861-1940) definiu as perturbações da consciência nas doenças afásicas como "desajustes da formulação e da expressão simbólicas" (Cassirer, 1972, p. 237). Com efeito, Head forjou um conceito geral acerca das patologias da linguagem que ordenava diversos fenômenos patológicos em torno do primado da atividade simbólica. Mais que isso, Head não confinou a função simbólica no campo da linguagem. Segundo o autor, o comportamento simbólico fazse presente em operações e atividades humanas cuja natureza é autônoma em relação ao fenômeno linguístico. Análises mais precisas da atividade motora mostram que o campo da ação revela o mesmo gênero de segmentação observado no domínio da linguagem. Há formas de ação que correspondem a uma efetuação motora imediata, reflexa, diretamente relacionada a uma excitação externa qualquer. Outras denotam uma orientação do pensamento que, como no campo da linguagem, devem ser agrupadas sob a égide de um pensamento simbólico. A partir do exame sistemático da atividade motora de um grande número de doentes afásicos, que deveriam realizar operações das mais fáceis e "imediatas" às mais complexas, Head concluiu que, entre as perturbações da linguagem e da ação, há uma perturbação mais fundamental, a saber, uma perturbação do comportamento simbólico (Cassirer, 1972).

\section{A atitude categorial, segundo Gelb e Goldstein}

Merleau-Ponty (1942/1967) faz menção às afasias amnésicas e, remetendo-se criticamente à teoria clássica das imagens verbais, afirma que os pacientes a quem cabe aquele diagnóstico não perderam as palavras, mas o poder de nomear. Essa atividade depende da tomada do objeto e da palavra enquanto representantes de uma categoria, atividade sustentada, justamente, pelo que Gelb e Goldstein denominaram atitude categorial. Um sujeito cuja experiência fora reduzida a seus aspectos concretos e imediatos encontra-se impossibilitado de exercer suas ocupações segundo a estrutura do comportamento marcada pela capacidade simbólica. Voltemo-nos aos trabalhos dos dois neuropsiquiatras e vejamos como essas questões são 
apresentadas.

Gelb (1933) e Goldstein (1934/1983, 1971a, 1971b, 1971c) submeteram pacientes acometidos por sintomas de afasia amnésica, mais precisamente por amnésia relativa aos nomes de cores, ao teste de visão de cores de Holmgreen. Trata-se de expor diante dos pacientes diversas fitas de lã coloridas, entre as quais diferentes formas de várias cores, no que tange à tonalidade e o brilho, devem estar representadas. Solicita-se, então, aos sujeitos que agrupem, por exemplo, as fitas que, segundo a cor fundamental, se ajustem a uma fita dada, da cor verde claro, azul escuro, etc. Ou, solicita-se a eles, simplesmente, que ordenem todas as fitas segundo suas cores fundamentais. Os pacientes mostravam-se incapazes de realizar corretamente as tarefas indicadas. Ora agrupavam duas fitas de nuances idênticas ou bastante parecidas e davam a tarefa por finalizada, ora se punham a agrupar fitas de cores cujo tom fundamental era absolutamente diferente, mas que se assemelhavam segundo o brilho. Poderia ocorrer, ainda, que certos pacientes arranjassem as fitas numa série crescente que fosse do tom mais claro ao mais escuro, realizando, então, uma "categorização" das fitas coloridas. Ora, a observação minuciosa da atividade do paciente, ou alguns questionamentos direcionados a ele acerca do seu procedimento no teste, revelava que, na realidade, os pacientes alinhavam as fitas por pares sucessivos. A cada vez, os sujeitos esforçavam-se para encontrar a fita da cor mais parecida com a da última que haviam alinhado à série. Os pacientes utilizavam um subterfúgio, uma estratégia para executar a tarefa, estratégia essa que nada tem a ver com má fé, mas com o empenho no cumprimento da mesma segundo os meios que lhes eram ainda disponíveis. De fato, os pacientes não chegavam a cumprir as exigências do exame senão em aparência (Gelb, 1933).

Em outro exemplo marcado pela ocorrência de ladeamento, o médico solicitava ao paciente que designasse a nuance que correspondia a um nome de cor qualquer, o vermelho, por exemplo. O exame de uma eventual resposta correta podia mostrar que o paciente apoiava-se em um saber verbal que lhe abria alguns caminhos. Ele podia lembrar que alguns objetos são designados como vermelho-sangue, reavivar uma imagem do sangue, e, então, chegar a uma resposta correta (Goldstein, 1971a). Goldstein (1971b) denomina este processo nomeação externa, ou pseudo-nomeação, que se apega a automatismos linguísticos e a conexões externas entre as palavras adquiridos em um período anterior à patologia, quando a fala era ainda sustentada por uma função representativa.

A pseudo-nomeação é ainda mais clara no caso de pacientes afásicos cujo principal sintoma manifesta-se no exercício de nomeação de objetos concretos. A um dos seus pacientes, Goldstein (1971b) mostrara um guarda-chuva e, então, formulara a simples questão: “O que é isso?". O paciente, ao invés de dizer: "Isso é um guarda-chuva", respondera: "Isso é uma coisa para a chuva. Eu tenho isso em casa". Então, repentinamente, o paciente disse: "Eu tenho três guarda-chuvas em casa".

Outro caso clínico ilustrativo refere-se a uma mulher de meia idade, secretária de extrema competência, e que, devido a uma trombose, sofrera uma lesão cerebral. A partir daí, a paciente passara a apresentar grandes variações na linguagem, ora com expressões e compreensão adequadas, ora com grande dificuldade para lembrar-se das palavras e para compreender adequadamente aquilo que lhe era dito. Ora, uma observação precisa do comportamento da paciente mostrou que as suas dificuldades não apareciam ao acaso, mas, sim, diante de situações e de tarefas perfeitamente determinadas. Raramente as palavras lhe faltavam diante de uma conversação voltada para as coisas concretas relativas ao seu meio. Assim, pois, diante da solicitação de enumerar prenomes femininos, nomes de animais ou de capitais de países, ela passava a balbucios, visto que as palavras não lhe surgiam. Essas palavras, ela ainda as possuía, diz Goldstein, visto que em outras situações ela as utilizava com segurança. Foi por meio da análise de um subterfúgio adotado pela paciente que os contextos que definiam o fracasso ou o sucesso dos seus esforços linguísticos ficaram claros. Diante de uma nova solicitação do médico, ela pronunciara, em série, quatro prenomes femininos; pronunciara, também em série, o nome de alguns animais. Interrogada sobre o modo como cumprira a tarefa, a paciente respondeu que enumerara o prenome das quatro irmãs que compõem sua família, e, quanto aos animais, citara o nome dos primeiros a serem vistos a partir da entrada no jardim zoológico da sua cidade. A paciente se apegara a lembranças de experiências diretas e concretas. "Evidentemente, essas palavras não representavam para ela designações de coisas, mas de qualidades do vivido; ela tornavase incapaz de encontrá-las quando desapegadas da experiência e independentes" (Goldstein, 1971a, p. 328).

O invariante entre os diversos sintomas da afasia amnésica foi, então, pouco a pouco, tornando-se claro: tratava-se da impossibilidade por parte dos pacientes de se desprender da experiência concreta e real, resume Merleau-Ponty (1942/1967). O fracasso dos doentes nos exames propostos era condicionado pela exigência de adentrar a esfera do possível, do concebido e do pensado. Daí advém a afirmação de Goldstein (1971a) de que as palavras não eram empregadas pelos pacientes conforme um sentido categorial, como um símbolo que representa uma ideia. Neles, o exercício da linguagem deixara de se realizar segundo uma estrutura conceitual e abstrata. Assim, Gelb e Goldstein concluem que seus pacientes sofriam pela deterioração, pelo enfraquecimento da atitude categorial ou comportamento simbólico.

É importante assinalar o fato de que essas expressões fazem menção ao âmbito geral da organização vital. É o organismo como um todo que deixa de se dispor segundo a atitude categorial no seu debate com o meio. É o que mostram as observações dos dois pesquisadores. A descrição fiel, atenta e minuciosa do comportamento dos doentes revela uma modificação da conduta em diversos domínios como a percepção, o conhecimento, a ação, o pensamento e a vida emocional, além da linguagem. Em todos esses domínios uma analogia estrutural é possível, o que faz do domínio até então privilegiado da linguagem uma expressão da adaptação do organismo atingido pela doença às suas novas condições e necessidades (Gelb, 1933). Podemos falar, assim, em uma "modificação fundamental" no comportamento dos doentes que outros pesquisadores como Head e Woerkom denominaram, respectivamente, como perturbação da "expressão simbólica" e da "função de representação". Merleau-Ponty (1942/1967) apropria-se dessas conclusões dizendo o que segue: 
O que é inacessível não é, pois, um certo estoque de movimentos, mas um certo tipo de ato, um certo nível de ação. Compreende-se, por conseguinte, que o distúrbio não se limita a uma faculdade particular, mas se encontra, em graus variáveis, em todas aquelas que exigem a mesma atitude de gratuidade. (p. 69)

Merleau-Ponty (1942/1967) faz referência, especialmente, aos estudos de Gelb, Goldstein e colaboradores acerca de um ferido de guerra designado pelos pesquisadores como Schneider. O paciente, vítima de um estilhaço de obus que lhe causara uma lesão na região occipital do córtex cerebral, apresentava perturbações em diversos domínios do comportamento: percepção, reconhecimento e lembrança visuais; reconhecimento espacial tátil; motricidade; memória; inteligência e linguagem. A julgar pela diversidade de sintomas, poder-se-ia optar pelo diagnóstico não de apenas uma, mas de simultâneas neuropatologias, além de associá-las a possíveis lesões múltiplas do córtex cerebral. Tratava-se, porém, mesmo, de uma única lesão, localizada, circunscrita em termos materiais ou anatômicos. Outra possibilidade: derivar os déficits diversos de apenas um deles. A perturbação da percepção visual foi o primeiro a ser observado e, na primeira publicação que Gelb e Goldstein dedicaram ao caso, recebera destaque. O diagnóstico foi ampliado a partir de estudos posteriores, conforme comentário de Merleau-Ponty ${ }^{5}$.

Ainda que os dois pesquisadores sublinhem as perturbações de caráter perceptivo em Schneider, diagnosticado entre as cegueiras psíquicas, o paciente apresentava déficits de linguagem, conforme apontamento anterior. À primeira vista, sua expressão verbal parecia intacta. Por outro lado, através do exame psiquiátrico, notava-se que suas expressões não emergiam jamais como linguagem representativa (Goldstein, 1971a). Sua linguagem aparecia subordinada à ação e à sua experiência concreta. É por isso que ele se mostrava incapaz de compreender expressões figuradas, de responder a perguntas simples, mas com um caráter teórico e desapegado ao que pudesse estar ocorrendo à sua volta, e é por isso, também, que ele nunca iniciava espontaneamente uma conversação, o que, no mais das vezes, exigiria que ele saísse da perspectiva pessoal à qual ele parecia atado. Se Schneider era capaz de desempenhar a contento algumas atividades da sua vida diária, era graças à sua linguagem involuntária, à recitação quase maquinal de frases que lhe conduziam às compreensões necessárias às suas tarefas (Gelb, 1933) e que, inclusive, preenchiam as lacunas da sua percepção deficitária (Goldstein, 1971a). Seu manejo da linguagem dava-se no sentido de uma atitude geral cuja estrutura era voltada para o concreto e para o imediato em oposição à atitude categorial, do mesmo modo que os pacientes portadores de afasia amnésica agrupavam as fitas coloridas sem a ideia precisa do princípio sobre o qual deveria girar o agrupamento; seu comportamento era guiado por uma espécie de intuição imediata (Gelb, 1933).

O que queremos mostrar através dessas comparações, e o que interessava tanto a Merleau-Ponty, é que o homem portador de uma lesão cerebral é um homem modificado, conforme as palavras de Gelb, ou tocado em sua essência, como diz Goldstein (1971a), e que essa modificação essencial encontra expressão em múltiplos domínios, inclusive no da linguagem - se bem que a localização da lesão possua uma importância fundamental na delineação dos déficits funcionais. O comprometimento do organismo possui um caráter estrutural, do mesmo modo que o comportamento saudável representa uma estrutura orgânica equilibrada e capaz de exercer diferentes níveis de ação, como diz Merleau-Ponty. O organismo humano saudável apresenta uma capacidade funcional elevada, sendo capaz de reações bastante heterogêneas e diferenciadas. Ao representarmos as ações do organismo em termos de processos figura-fundo, raciocínio caro a Goldstein, poderíamos dizer que a diferenciação e a precisão das reações orgânicas dependem da formação adequada de figuras, ou processos neurofisiológicos de primeiro plano, sob a base formada pelos processos no resto do sistema ou mesmo no restante do organismo total. As estimulações geradas no organismo normal desencadeiam processos figurais estáveis em regiões determinadas do sistema, processos tais que se desenvolvem sobre o plano de fundo orgânico. A este processo figura e fundo, no âmbito fisiológico, corresponde uma atividade figura e fundo no plano funcional.

É sob esta perspectiva que Merleau-Ponty (1967) compara as perturbações de Schneider com as de um paciente estudado por Boumann e Grünbaum. Os déficits apresentados pelos dois pacientes são, à primeira vista, bastante diferentes. Enquanto Schneider, a despeito de seus déficits visuais, era capaz de reconhecer alguns objetos centrando-se na análise de alguns detalhes da sua configuração, por exemplo, o reconhecimento de um dado a partir dos pontos pretos na sua superfície, o paciente de Boumann e Grünbaum era incapaz de perceber os detalhes das coisas. Schneider era mesmo perturbado pelo modo como os detalhes saltavam aos seus olhos, impedindo a apreensão das características essenciais do objeto percebido. Ora, a incapacidade de ver além dos detalhes e a incapacidade de percebê-los não implica uma deficiência de forma idêntica? "Os dois doentes apresentam a mesma deficiência fundamental da "estrutura figura e fundo"' (Merleau-Ponty, 1967, p. 72).

As dificuldades que os pacientes com diagnóstico de afasia amnésica apresentam no teste de visão de cores de Holmgreen podem ser discutidas a partir dessa mesma perspectiva. Vimos que os pacientes ao invés de agruparem as fitas segundo a cor fundamental, conforme a instrução do médico, podem passar a agrupá-las com base no brilho, e, em seguida, repentinamente, agrupá-las ainda sob um outro critério qualquer, atividade que se destaca pelo seu caráter lábil (Gelb, 1933). Como um indivíduo saudável executa a tarefa de agrupar as fitas? Ele a executa segundo um princípio de classificação, que pode variar, obviamente, mas que, a partir do momento em que é definido, seja por escolha do sujeito, seja por instrução do examinador, dirige a sua atividade. Gelb (1933) comenta:

Uma vez fixado um princípio de classificação, qualquer que seja ele, "vemos" as cores sob um outro aspecto; as amostras isoladas não são mais tomadas no seu ser atual, mas consideradas, antes, como representantes de propriedades da cor que escolhemos como princípio de classificação; os exemplares isolados tornam-se os representantes de certas categorias de cores (grifos do autor). (p. 411) 
O fato é que os exemplares da categoria definida emergem como figura sobre um plano de fundo composto por fitas de outras cores e que deixam, então, de representar aspectos essenciais na situação descrita. Daí sobrevém a seguinte afirmação de Merleau-Ponty (1967):

Como o comportamento do doente adere, muito mais estreitamente do que aquele do normal, às relações concretas $\mathrm{e}$ imediatas do meio, o distúrbio fundamental poderá ainda ser definido como 'a incapacidade de captar o essencial de um processo' ou, enfim, como a incapacidade de destacar nitidamente um conjunto percebido, concebido, ou apresentado, a título de figura, sobre um fundo tratado como indiferente (grifos do autor). (p. 69)

$\mathrm{Na}$ continuação deste trecho, Merleau-Ponty insere outra ideia, também fundamental para nós. "A transformação patológica ocorre no sentido de um comportamento menos diferenciado, menos organizado, mais global, mais amorfo", diz ele (Merleau-Ponty, 1967, pp. 69-70). O comportamento total é agora expressão de uma alteração fundamental, possui uma nova significação devida a uma desintegração sistemática funcional em que "as dimensões originais da atividade orgânica e humana" (Merleau-Ponty, 1967, p. 81) foram danificadas.

Nas palavras de Gelb (1933) a modificação essencial que vem sendo delimitada representa "uma regressão na direção de um comportamento menos abstrato, menos racional, mais imediato e mais concreto, portanto neste sentido mais primitivo" (grifos do autor) (p. 408). Merleau-Ponty (1967), ao finalizar sua comparação entre Schneider e o paciente de Boumann e Grümbaum, comenta, citando Goldstein: "em todos esses domínios [atenção, pensamento, linguagem espontânea, etc.] 'o processo psíquico ou psicomotor encontra-se fixado numa fase primitiva do desenvolvimento que vai de uma impressão de conjunto amorfa a uma estruturação (Ausgestaltung) mais diferenciada"". Além disso, Merleau-Ponty (1967) compara a percepção infantil, mais sincrética e ao mesmo tempo capaz de ser mais minuciosa, à alteração estrutural dos pacientes em questão.

Goldstein (1971a), em artigo posterior àquele citado por Merleau-Ponty, é categórico ao afirmar que a linguagem utilizada pelas crianças não pode ser assimilada à utilizada pelos afásicos. É comum que a criança, para quem a palavra é aderente às coisas, acompanhe suas ações pela fala, associação que pouco a pouco cede espaço completamente à ação sem verbalização. Ora, o doente exposto a uma situação concreta, em que uma criança faria acompanhar seus atos por palavras, não exprime suas ações pela fala, acompanhamento extinto há muito. Em uma situação concreta que lhe solicita uma reação imediata, seja motora ou linguística, o paciente provavelmente se sairá bem, realizando o ato adequado diante da solicitação motora e emitindo a palavra adequada diante da solicitação de cunho linguístico. Se, no entanto, lhe solicitamos que exprima em palavras as suas ações, exigimos dele justamente a atividade perturbada pela alteração da atitude categorial, demandamos que ele utilize palavras como signos, diz Goldstein, e, então, ele falhará. Por sua vez, Gelb (1933) contrapõe-se à assimilação do comportamento dos doentes a uma mentalidade primitiva, na perspectiva da antropologia tradicional de Levy-Brühl. Se com esta expressão, faz-se referência a culturas cujo contato com o mundo assentase em um caráter mítico, Gelb cita Cassirer, para quem o mito e o conhecimento científico e filosófico possuem uma mesma origem ontológica. As críticas de Lévi-Strauss (1962/2007) às análises etnocêntricas que evocam a "inaptidão dos 'primitivos' ao pensamento abstrato" (p. 11) são pertinentes nesse ponto da discussão. A partir do exame de inúmeras línguas indígenas, o autor refere-se à sua riqueza em palavras abstratas, que designam propriedades e qualidades dos seres e das coisas. Lévi-Strauss (2007) faz referência, ainda, a procedimentos de observação e de categorização que implicam uma circunspecção por parte dos indígenas comparável aos métodos da ciência moderna.

Em suma, tratamos aqui de referências específicas ao organismo humano, que atingira sua maturidade no contexto das sociedades modernas ocidentais, e que apresenta lesões que causam danos estruturais no comportamento e que, por conseguinte, alteram de modo essencial o contato do sujeito com o mundo. Trata-se, portanto, de uma nova significação, de uma nova estrutura do comportamento, da qual não podemos dizer que esteja reduzida às suas formas vitais, e, sim, que implica uma atitude da parte do doente para com o mundo modificada. Suas operações conservadas, o que Jackson denomina sintomas positivos, são diretamente correlacionadas ao estreitamento do meio em que vive. O comportamento ordenado do doente depende dessa redução proporcional ao déficit ${ }^{6}$. Sabemos que o meio é recortado no mundo a partir do ser do organismo. Assim, se o meio habitual do doente tornou-se um meio perturbador devido aos déficits apresentados, a existência do indivíduo depende, então, da sua capacidade de extrair do mundo um ambiente que lhe seja adequado, no caso dos pacientes aqui considerados, um meio em que o comportamento simbólico, ou categorial, não seja constantemente solicitado. Além disso, no caso do sintoma da lesão, as capacidades funcionais orgânicas mais relevantes dentre as ainda passíveis de atualização serão mantidas, e sempre no nível mais elevado possível no que tange ao funcionamento do organismo total (Goldstein, 1983).

\section{Considerações finais}

Em meio aos estudos do início do século XX sobre a afasia, acompanhamos a passagem de concepções localizacionistas e associacionistas a concepções globalistas acerca do funcionamento nervoso. Essa transição tornou-se possível a partir de uma conversão mais profunda que diz respeito à teoria do conhecimento biológico e psicológico. Consideramos as análises de Merleau-Ponty (1942/1967) acerca de novas atitudes de pesquisa que, abandonando concepções teóricas préestabelecidas, se apegam aos aspectos concretos da observação clínica e atém-se à compreensão da fisionomia do conjunto fenomênico estudado, no caso que nos ocupa, as perturbações comportamentais devidas a lesões cerebrais. Foi a partir de uma nova conjunção epistemológica que as afasias passaram a ser estudadas enquanto índice da alteração do comportamento simbólico. As atividades do homem podem ser exercidas segundo uma estrutura conceitual e abstrata, que representa nossa possibilidade de afastamento em relação à experiência concreta 
imediata. No caso de lesões cerebrais, o organismo como um todo pode deixar de se dispor no mundo segundo a atitude simbólica.

$\mathrm{O}$ estudo do simbolismo na antropologia, na psicologia e na filosofia é uma herança comum dos estudos em neuropsicopatologia do início do século XX abordados neste artigo. A referência aos autores aos quais nos reportamos é frequente nos trabalhos de Marcel Mauss, de Henri Delacroix, de Henri Wallon e de Piaget, por exemplo (Karsenti, 1997).

Quanto a Merleau-Ponty, a partir da perspectiva assumida em seu segundo livro, Fenomenologia da percepção (1945), e que visa a encarnação da ideia de consciência na medida em que se assevera o primado do corpo enquanto sujeito da percepção, a concepção de que uma função simbólica possa sustentar o caráter objetivante da percepção tomba como uma abstração, fruto de prejuízos intelectualistas. Assim, o filósofo passa a combater, tanto na neuropsiquiatria quanto na filosofia, o que considera representar uma crescente autonomia da ideação simbólica na dinâmica entre conteúdo e forma da percepção.

\section{Referências}

Bergson, H. (1970). Matière et mémoire: essai sur la relation du corps a l'esprit. In H. Bergson (Org.), Oeuvres (pp.159-379). Paris: Presses Universitaires de France.

Bimbenet, E. (2007). Merleau-Ponty au seuil des sciences humaines. Chiasmi International, 9, 31-45.

Binswanger, L. (1971). Introduction a l'analyse existentielle (J. Verdeaux \& R. Kuhn, Trads.). Paris: Les Éditions de Minuit.

Cabanis, P. (1956). Rapports du physique et du moral de l'homme. In C. Lehec \& J. Cazeneuve (Orgs.), Oeuvres philosophiques de Cabanis. Paris: Presses Universitaires de France.

Cassirer, E. (1972). La philosophie des formes symboliques: la phénoménologie de la connaissance (Vol. 3, C. Fronty, Trad.). Paris: Les Éditions de Minuit.

Forest, D. (2005). Histoire des aphasies. Paris: Presses Universitaires de France.

Gelb, A. (1933). Remarques générales sur l'utilisation des donnés pathologiques pour la psychologie et la philosophie du langage. Journal de Psychologie
Normale et Pathologique, 30, 403-429.

Goldstein, K. (1971a). L'analyse de l'aphasie et l'étude de l'essence du langage. In A. Gurwitsch, E. Haudek, \& W. Haudek (Orgs.), Kurt Goldstein: selected papers/Ausgewählte Schreften (pp. 282-344). Netherlands: Martinus Nijhoff/ The Hague.

Goldstein, K. (1971b). The problem of the meaning of words based upon observation of aphasic patients. In A. Gurwitsch, E. Haudek, \& W. Haudek (Orgs.), Kurt Goldstein: selected papers/Ausgewählte Schreften (pp. 345359). Netherlands: Martinus Nijhoff/The Hague.

Goldstein, K. (1971c). Significance of speech disturbances for normal psychology. In A. Gurwitsch, E. Haudek, \& W. Haudek (Orgs.), Kurt Goldstein: selected papers/Ausgewählte Schreften (pp. 360-364). Netherlands: Martinus Nijhoff/ The Hague.

Goldstein, K. (1983). La structure de l'organisme. (E. Burckdardt \& J. Kuntz, Trads.). Paris: Gallimard. (Trabalho original publicado em 1934)

Husserl, E. (1963). Recherches logiques: éléments d'une élucidation phénoménologique de la connaissance (Vol.3: Recherche VI). Paris: Paria Universitaires de France. (Trabalho original publicado em 1921)

Karsenti, B. (1997). L'homme total: sociologie, anthropologie et philosophie chez Marcel Mauss. Paris: Presses Universitaires de France.

Kristensen, C., Almeida, R., \& Gomes, W. (2001). Desenvolvimento histórico e fundamentos metodológicos da neuropsicologia cognitiva. Psicologia: Reflexão e Crítica, 14 (2), 259-274.

Lecours, A., \& Lhermitte, F. (1979). De Franz Gall à Pierre Marie. In A. Lecours, \& F. Lhermitte (Orgs.), L'aphasie (pp. 27-35). Paris/Québec: Flammarion/ Les Presses de l'Université de Montréal.

Lévi-Strauss, C. (2007). La pensée sauvage. Paris: Plon. (Trabalho original publicado em 1962)

Merleau-Ponty, M. (1945). Phénoménologie de la perception. Paris: Gallimard.

Merleau-Ponty, M. (1967). La structure du comportement (6 $6^{\underline{a}}$ ed.). Paris: Presses Universitaires de France. (Trabalho original publicado em 1942)

Minkowski, E. (1995). Le temps vécu: études phénoménologiques et psychopathologiques. Paris: Quadrige/Presses Universitaires de France. (Texto original publicado em 1933)

Straus, E. (1966). Psicología fenomenológica. Buenos Aires: Paidós.

Verissimo, D., \& Furlan, R. (2006). Merleau-Ponty e a evolução espontânea da psicologia. Temas em Psicologia, 20(2), 143-152. 
1. Ao longo de toda sua carreira, Merleau-Ponty recorreu às ciências, principalmente às ciências humanas. Longe de mostrar-se um acessório, este recurso à psicopatologia, à psicologia, à sociologia, à linguística, revela-se elemento constitutivo do seu discurso filosófico. Com efeito, seu pensamento nutre-se dos elementos ontológicos presentes nos problemas que ocupam estas ciências. Além disso, tem-se em Merleau-Ponty um atento observador do processo de autocrítica que as ciências humanas operam incessantemente (Bimbenet, 2007; Verissimo \& Furlan, 2006). Daí sua importância enquanto intérprete das transformações metodológicas e conceituais no que tange aos estudos sobre a afasia e a noção de comportamento simbólico que delas emergiu.

2. Remetemos o leitor, especialmente, à obra de Cassirer (1972), que dedica um importante espaço às patologias da consciência simbólica.

3. Cabanis (1956, p. 126) afirma: "é fácil sentir que o conhecimento físico do homem é a base comum entre elas [as ciências do homem]; que este é o ponto de onde elas todas devem partir".

4. Bergson (1970) discute as concepções materialistas da afasia. As dificuldades teóricas às quais fazemos menção aqui foram importantes para o filósofo na refutação daquelas concepções.

5. Conferir Merleau-Ponty, 1967, p. 71, nota 2, e p. 130, nota 3. Conferir, também, Merleau-Ponty, 1945, p. 132, nota 2.

6. Conferir Goldstein, 1983, p. 42.

Danilo Saretta Verissimo, doutor em Psicologia pela Universidade de São Paulo e doutor em Filosofia pela Université Jean Moulin - Lyon 3, é professor Assistente na Universidade Estadual Paulista de Assis. Endereço para correspondência: Faculdade de Ciências e Letras de Assis - UNESP, Departamento de Psicologia Evolutiva, Social e Escolar, Avenida Dom Antônio, 2100, Assis-SP. CEP 19806-900. Tel.: (18) 3321-1060. E-mail: danilo.verissimo@gmail.com 